\title{
In Vitro Susceptibility of Mycobacterium ulcerans to Clarithromycin
}

\author{
F. PORTAELS,${ }^{1 *}$ H. TRAORE, ${ }^{1}$ K. DE RIDDER,${ }^{1}$ AND W. M. MEYERS ${ }^{2}$ \\ Department of Microbiology, Institute of Tropical Medicine, Antwerp, Belgium, ${ }^{1}$ and \\ Armed Forces Institute of Pathology, Washington, D.C. 20306-6000 2
}

Received 9 March 1998/Returned for modification 13 April 1998/Accepted 1 June 1998

\begin{abstract}
Buruli ulcer (BU), caused by Mycobacterium ulcerans, was recently recognized by the World Health Organization as an important emerging disease. While antimycobacterial therapy is often effective for the earliest nodular or ulcerative lesions, medical management of $\mathrm{BU}$ lesions in patients presenting for treatment is usually disappointing, leaving wide surgical excision the only alternative. Advanced ulcerated lesions of BU rarely respond to antimycobacterial agents; however, perioperative administration of such drugs may prevent relapses or disseminated infections. Clarithromycin possesses strong activity in vitro and in vivo against most nontuberculous mycobacteria. In this study we determined the antimycobacterial activity of this drug in vitro against 46 strains of $M$. ulcerans isolated from 11 countries. The MIC of clarithromycin was determined at $\mathrm{pH}$ 6.6 (on 7H11 agar) and at pH 7.4 (on Mueller-Hinton agar). The MICs ranged from 0.125 to $2 \mu \mathrm{g} / \mathrm{ml}$ at $\mathrm{pH}$ 6.6 and from $<0.125$ to $0.5 \mu \mathrm{g} / \mathrm{ml}$ at $\mathrm{pH}$ 7.4. For the majority of the strains, geographic origin did not play a significant role. Thirty-eight strains $(83 \%)$ were inhibited by $0.5 \mu \mathrm{g} / \mathrm{ml}$ at $\mathrm{pH} 7.4$. These MICs are below peak therapeutic concentrations of clarithromycin obtainable in blood. These results suggest that clarithromycin is a promising drug both for the treatment of early lesions of $M$. ulcerans and for the prevention of hematogenous dissemination of the etiologic agent during and after surgery. Studies should be initiated to evaluate the effects of clarithromycin in combination with ethambutol and rifampin on $M$. ulcerans both in vitro and in experimentally infected mice. Multidrug regimens containing clarithromycin may also help control the secondary bacterial infections sometimes seen in BU patients, most importantly osteomyelitis.
\end{abstract}

Mycobacterium ulcerans causes necrotizing, relatively nonpainful lesions known variously as Buruli ulcer (BU), Bairnsdale ulcer, or more precisely, M. ulcerans infection. BU was recently recognized by the World Health Organization as an important emerging disease. The disease has been reported in many countries, mostly tropical, in Africa, North America (Mexico), South America, Southeast Asia, and Australia. Recent reports have suggested increased incidences of BU in, for example, some areas of Benin (21), Australia (13), and Côte d'Ivoire (24).

Medical treatment of these ulcers is usually disappointing, leaving wide surgical excision followed by skin grafting the only alternative (4). Preulcerative nodular lesions and early small ulcerated lesions can be effectively treated by excision and primary closure, by rifampin alone, or possibly by heating at $40^{\circ} \mathrm{C}$ without prior excision (26). Rifampin, however, is usually not effective against advanced ulcers. Even though currently the best therapeutic approach is surgery, it is possible that postsurgical antimycobacterial treatment would prevent relapses or metastatic infections. Disseminated infections with involvement of bone and cartilage have been observed $(3,10)$.

Among the new macrolides, clarithromycin possesses strong activity in vitro and in vivo against most nontuberculous mycobacteria. Clarithromycin is effective for the treatment of infections caused by Mycobacterium avium complex in AIDS patients $(8,11)$, Mycobacterium genavense (5) and Mycobacterium haemophilum (22) infections, lymphadenitis caused by nontuberculous mycobacteria (36), and Mycobacterium marinum infections in both human immunodeficiency virus-sero-

* Corresponding author. Mailing address: Institute of Tropical Medicine, Nationalestraat 155, B-2000 Antwerp, Belgium. Phone: 323247 63 24. Fax: 32324763 33. E-mail: portaels@itg.be. negative and -seropositive patients (6). Numerous investigations have shown clarithromycin to be active in the treatment of infections caused by rapidly growing mycobacteria $(7,25,28$, $30,37,38)$, and it is active in vitro and in vivo against $M$. avium (12) and Mycobacterium leprae (14).

Several reports suggest that the susceptibilities of some mycobacterial species to clarithromycin depend on the $\mathrm{pH}$ of the medium and that the MIC of clarithromycin for these species is lower at pH 7.4 than at $\mathrm{pH} 6.6(20,32)$.

Based on the reported efficacy of clarithromycin for the treatment of leprosy and some other nontuberculous mycobacterial infections, we determined the antimycobacterial activities of this drug in vitro at $\mathrm{pH} 6.6$ and at $\mathrm{pH} 7.4$ against strains of $M$. ulcerans of different geographic origins. We chose to assess the MIC at $\mathrm{pH} 6.6$ and 7.4 because $\mathrm{pH} 6.6$ is the standard $\mathrm{pH}$ of $7 \mathrm{H} 11$ medium, which is commonly used for drug sensitivity tests and determination of the MIC for mycobacteria (19), and because the physiological $\mathrm{pH}$ of plasma is 7.4.

\section{MATERIALS AND METHODS}

Antimicrobial agent. Clarithromycin was kindly provided by Abbott Laboratories Ltd. (Queenborough, Kent, England). The stock solution $(2 \mathrm{mg} / \mathrm{ml})$ and working solutions were prepared as described by Mor and Heifets (27).

MIC determination. Because the antimycobacterial efficacy of clarithromycin depends on the $\mathrm{pH}$ of the medium, the MIC of clarithromycin was determined on two different media: 7H11 agar $(\mathrm{pH}$ 6.6) and Mueller-Hinton agar $(\mathrm{pH} 7.4)$ supplemented with $10 \%$ (vol/vol) OADC (oleic acid, albumin, dextrose, and catalase; Difco Laboratories, Detroit, Mich.) $(20,32)$. Both media contained twofold dilutions of clarithromycin from 0.125 to $4 \mu \mathrm{g} / \mathrm{ml}$. Media without antibiotics added served as controls. The inocula were $0.1 \mathrm{ml}$ of $10^{-1}$ and $10^{-3}$ dilutions of bacterial suspensions of $1 \mathrm{mg} / \mathrm{ml}$ in phosphate-buffered saline. The tubes were incubated at $33^{\circ} \mathrm{C}$ and were read after 28 and 42 days of incubation. The MIC was defined as the lowest concentration of clarithromycin inhibiting $\geq 99 \%$ of the bacterial population in the $10^{-1}$ dilution. Only tests with growth in the tubes inoculated with the $10^{-3}$ dilution were considered valid.

Bacterial strains. A total of $46 \mathrm{M}$. ulcerans strains isolated from patients from 11 countries were studied (see Table 1). One ATCC reference strain, ATCC 
TABLE 1. MICs of clarithromycin against 46 isolates of M. ulcerans from 11 different countries

\begin{tabular}{|c|c|c|c|c|c|c|c|c|c|}
\hline \multirow{2}{*}{$\begin{array}{l}\text { Origin }(n) \text { of } \\
\text { isolates }\end{array}$} & \multirow{2}{*}{$\mathrm{pH}$} & \multirow{2}{*}{ No. tested } & \multicolumn{7}{|c|}{$\begin{array}{l}\text { Cumulative } \% \text { of strains inhibited at the } \\
\text { following MIC }(\mu \mathrm{g} / \mathrm{ml}):\end{array}$} \\
\hline & & & $<0.125$ & 0.125 & 0.25 & 0.50 & 1 & 2 & 4 \\
\hline \multirow{2}{*}{$\begin{array}{l}\text { Australia } \\
\text { (12) }\end{array}$} & 6.6 & 12 & & & & 42 & 92 & 100 & \\
\hline & 7.4 & 8 & 88 & & & 100 & & & \\
\hline \multirow[t]{2}{*}{ Benin (9) } & 6.6 & 7 & & 43 & 57 & 86 & 100 & & \\
\hline & 7.4 & 6 & 33 & & 100 & & & & \\
\hline \multirow{2}{*}{$\begin{array}{l}\text { Côte d'Ivoire } \\
\text { (5) }\end{array}$} & 6.6 & 5 & & & 20 & 100 & & & \\
\hline & 7.4 & 4 & & 25 & 75 & 100 & & & \\
\hline \multirow{2}{*}{$\begin{array}{l}\text { Democratic } \\
\text { Republic } \\
\text { of Congo } \\
\text { (8) }\end{array}$} & 6.6 & 8 & & 25 & 63 & 88 & 100 & & \\
\hline & 7.4 & 4 & 20 & & 100 & & & & \\
\hline \multirow[t]{2}{*}{ Ghana (4) } & 6.6 & 4 & & & 100 & & & & \\
\hline & 7.4 & 4 & & 25 & 75 & 100 & & & \\
\hline \multirow[t]{2}{*}{ Angola (1) } & 6.6 & 1 & & & 100 & & & & \\
\hline & 7.4 & 1 & & & 100 & & & & \\
\hline \multirow[t]{2}{*}{ Togo (1) } & 6.6 & 1 & & & & 100 & & & \\
\hline & 7.4 & 1 & 100 & & & & & & \\
\hline \multirow{2}{*}{$\begin{array}{l}\text { French } \\
\quad \text { Guiana (1) }\end{array}$} & 6.6 & 1 & & & & 100 & & & \\
\hline & 7.4 & 1 & & 100 & & & & & \\
\hline Mexico (1) & 6.6 & 1 & & 100 & & & & & \\
\hline $\begin{array}{l}\text { Papua New } \\
\text { Guinea (3) }\end{array}$ & 6.6 & 3 & & & 67 & 100 & & & \\
\hline Malaysia (1) & 6.6 & 1 & & & & & & 100 & \\
\hline
\end{tabular}

19423, from Australia, was studied. A total of 41 strains were isolated at the Institute of Tropical Medicine from tissue fragments transported to Antwerp (31), and 5 strains were obtained from other laboratories: 4 (1 from Papua New Guinea and 3 from Malaysia) were contributed by K. Jackson (Fairfield Hospital, Melbourne, Australia), and 1 (from French Guiana) was contributed by V. Vincent, Institut Pasteur, Paris, France.

Fresh subcultures were made on tubes of Löwenstein-Jensen medium.

\section{RESULTS}

As indicated in Table 1, the MICs of clarithromycin for the 44 M. ulcerans strains tested on 7H11 medium ( $\mathrm{pH}$ 6.6) ranged from 0.125 to $2 \mu \mathrm{g} / \mathrm{ml}$ and the MICs for the 29 strains tested on Mueller-Hinton medium ( $\mathrm{pH} 7.4$ ) ranged from $<0.125$ to 0.5 $\mu \mathrm{g} / \mathrm{ml}$. All tested strains were inhibited by $2 \mu \mathrm{g}$ of clarithromycin per $\mathrm{ml}$, and all but one Australian and one Malaysian strain were inhibited by $1 \mu \mathrm{g} / \mathrm{ml}$ (at $\mathrm{pH}$ 6.6).

Of the 46 strains tested at $\mathrm{pH} 6.6$ and/or $\mathrm{pH} 7.4,38$ strains (83\%) were inhibited by $0.5 \mu \mathrm{g} / \mathrm{ml}$. For six Australian strains and one strain each from Benin and the Democratic Republic of Congo (formerly Zaire), the MICs were $>0.5 \mu \mathrm{g} / \mathrm{ml}$.

For some of the strains, the MICs obtained at $\mathrm{pH} 7.4$ were 1 or more dilutions lower than those obtained at $\mathrm{pH}$ 6.6. MICs for 11 strains ( 7 from Australia, 2 from Benin, 1 from the Democratic Republic of Congo, and 1 from Togo) were $\leq 0.125 \mu \mathrm{g} / \mathrm{ml}$ when these strains were tested at $\mathrm{pH}$ 7.4. The
MICs obtained on 7H11 agar (pH 6.6) for the Australian and Malaysian strains were higher by 1 to 2 dilutions than those for strains from other countries.

The MIC of clarithromycin for the ATCC reference strain, ATCC 19423 , was $0.5 \mu \mathrm{g} / \mathrm{ml}$ on $7 \mathrm{H} 11$ medium $(\mathrm{pH} \mathrm{6.6)}$ and $<0.125 \mu \mathrm{g} / \mathrm{ml}$ on Mueller-Hinton agar ( $\mathrm{pH} 7.4$ ).

\section{DISCUSSION}

The MICs for the 46 M. ulcerans strains tested at $\mathrm{pH} 6.6$ and/or at $\mathrm{pH} 7.4$ varied from $\leq 0.125$ to $2 \mu \mathrm{g}$ of clarithromycin per $\mathrm{ml}$. For 1 Australian and 1 Malaysian strain (the latter tested at pH 6.6 only), the MIC was $2 \mu \mathrm{g} / \mathrm{ml}$, while the other 44 strains were inhibited by concentrations lower than $2 \mu \mathrm{g} / \mathrm{ml}$. These MICs are below peak plasma concentrations of clarithromycin obtainable in humans. Administration of $500 \mathrm{mg}$ of clarithromycin twice daily for up to 3.5 days to volunteers resulted in mean peak plasma concentrations between 2.4 and $3.5 \mu \mathrm{g} / \mathrm{ml}(9)$.

For the majority of strains, geographic origin did not seem to play a significant role in sensitivity to clarithromycin. The Australian and the Malaysian strains, nevertheless, were more resistant; MICs for these strains ranged from 0.5 to $2 \mu \mathrm{g} / \mathrm{ml}$. Genetic and phenotypic differences have been demonstrated between different strains of M. ulcerans (31). Whether these genetic and phenotypic differences (28) are related to susceptibility to antimycobacterial agents is unknown.

Low clarithromycin MICs have been obtained in vitro for other mycobacterial species; for example, with the BACTEC system, Rastogi and Goh (32) found low MICs for three $M y$ cobacterium bovis BCG strains $(0.25$ to $0.5 \mu \mathrm{g} / \mathrm{ml}$ at $\mathrm{pH} 6.8$ and 0.1 to $0.2 \mu \mathrm{g} / \mathrm{ml}$ at $\mathrm{pH}$ 7.4). These authors found MICs lower than $1 \mu \mathrm{g} / \mathrm{ml}$ at $\mathrm{pH} 6.8$ and 7.4 for several other mycobacterial pathogens, including Mycobacterium xenopi, Mycobacterium scrofulaceum, Mycobacterium kansasii, Mycobacterium chelonae, and M. marinum. Using the broth microdilution method with Mueller-Hinton medium ( $\mathrm{pH} 7.4$ ), Brown et al. (7) found that $90 \%$ of Mycobacterium chelonae subsp. chelonae organisms and $90 \%$ of Mycobacterium chelonae subsp. abscessus organisms were inhibited by 0.25 and $0.5 \mu \mathrm{g}$ of clarithromycin $/ \mathrm{ml}$, respectively. Rastogi and colleagues (33) also have reported clarithromycin activity against $M$. marinum and Mycobacterium paratuberculosis (MICs, 0.25 to $0.5 \mu \mathrm{g} / \mathrm{ml}$ ). MICs at $\mathrm{pH} 7.4$ in liquid media were $2 \mu \mathrm{g} / \mathrm{ml}$ or lower for $M$. avium strains (20). These results strongly suggest that clarithromycin is a promising chemotherapeutic agent for infections caused by a variety of mycobacterial species.

Because the inhibitory activity of clarithromycin is higher at $\mathrm{pH} 7.4$ than at an acid $\mathrm{pH}$, this drug may be especially effective for the elimination of extracellular bacteria and suppression of mycobacterial bacteremia. Heifets et al. (20) suggested that the elimination of $M$. avium from the blood of patients with AIDS under clarithromycin therapy was most likely related to the increased inhibitory activity of this drug at $\mathrm{pH}$ 7.4.

Clinical studies have repeatedly revealed that antimycobacterial agents are not effective for the treatment of advanced ulcerated lesions of BU. This is believed to be related to the low drug levels obtainable in the necrotic tissues of advanced BU in the skin. Extensive histopathologic studies demonstrate that $M$. ulcerans is essentially an extracellular parasite largely confined to areas of necrosis in skin; however, the bacillus often spreads to local and regional lymph nodes and causes metastatic disease in bone (1). In our report on $867 \mathrm{BU}$ patients treated at Zangnanado (3), we observed disseminated lesions following the appearance of the primary lesion. In some instances the disseminated lesions appeared after complete 
healing of the initial lesion. Such lesions probably represent hematogenous spread that may be preventable by effective antimycobacterial agents.

The present study demonstrates that levels of clarithromycin that are obtainable in blood are inhibitory for M. ulcerans in vitro. Thus, clarithromycin offers promise, not only for the treatment of early lesions of $M$. ulcerans, but also as an adjunct treatment for the prevention of hematogenous dissemination of the etiologic agent. The efficacy of rifampin against $M$. ulcerans in vitro and in vivo in the mouse has been established. The in vitro susceptibility of $M$. ulcerans to rifampin was found to be similar to that of Mycobacterium tuberculosis $(18,29,34)$. Early nodular lesions and early limited ulcerated lesions in humans respond favorably to rifampin monotherapy (23). Rifampin, thus, could also be a useful drug for the prevention of dissemination.

Combined therapy is generally recommended for the treatment of mycobacterial infections in order to prevent the development of resistance when the infection is caused by a sufficiently large number of bacilli to allow for the selection of resistant mutants. Most BU patients, at some stage of the disease, have massive bacillary burdens. Multiple-drug therapy may also produce additive or mutually synergistic effects between the antibacterial agents. Although M. ulcerans is resistant in vitro to ethambutol (data not shown), several reports indicate that ethambutol is synergistic with other antimycobacterial agents $(16,33)$. Clarithromycin shows synergism with rifampin in combined therapy of $M$. avium complex infections, and ethambutol enhances the bactericidal activity of rifampin against the same $M$. avium strains $(35,39)$. It was, however, recently demonstrated that rifabutin in combination with clarithromycin substantially reduced clarithromycin levels (17). Although rifampin or clarithromycin alone may be used in the treatment of patients with BU, studies should be initiated to evaluate the effects of clarithromycin alone and in combination with ethambutol and rifampin on M. ulcerans, both in vitro and in vivo in experimentally infected mice. Such studies would give valuable information for the formulation of recommendations for an optimal antimycobacterial regimen for use (i) as a treatment of certain stages of M. ulcerans infection, (ii) for the prevention of dissemination during or after surgery, and (iii) as an adjunct to other therapeutic approaches. Secondary bacterial infections are common in BU patients, especially in patients with osteomyelitis (2). Multidrug regimens containing clarithromycin might help control the complications of BU, which are often mutilating and sometimes life threatening.

Finally, regimens containing rifampin and ethambutol would avoid the selection of resistant mutants in patients who may have undiagnosed $M$. tuberculosis infection.

\section{ACKNOWLEDGMENTS}

This study was supported by the Damien Foundation (Brussels, Belgium).

We are grateful to K. Jackson for providing strains of M. ulcerans from Papua New Guinea and Malaysia and to V. Vincent for providing the strains from French Guiana. We thank R. Womersley, Abbott Laboratories Ltd., for kindly providing clarithromycin.

\section{REFERENCES}

1. Abalos, F., et al. Unpublished data.

2. Abalos, F., J. Aguiar, A. Guédénon, W. M. Meyers, and F. Portaels. 1997. Mycobacterium ulcerans infection. Am. J. Trop. Med. Hyg. 57:219. (Abstract 348.).

3. Aguiar, J., M. C. Domingo, A. Guédénon, W. M. Meyers, C. Steunou, and F. Portaels. 1997. L'ulcère de Buruli, une maladie mycobactérienne importante et en recrudescence au Bénin. Bull. Séances Acad. R. Sci. Outre-Mer 3:325358.

4. Aguiar, J., and C. Steunou. 1997. Les ulcères de Buruli en zone rurale au
Bénin: prise en charge de 635 cas. Med. Trop. 57:83-96.

5. Berman, S. M., R. C. Kim, D. Haghighat, M. E. Mulligan, J. Fierer, and F. C. Wyle. 1994. Mycobacterium genavense infection presenting as a solitary brain mass in a patient with AIDS: case report and review. Clin. Infect. Dis. 19:1152-1154.

6. Bonnet, E., D. Debat-Zoguereh, N. Petit, L. Ravaux, and H. Gallais. 1994. Clarithromycin: a potent agent against infections due to Mycobacterium marinum. Clin. Infect. Dis. 18:664-666.

7. Brown, B. A., R. J. Wallace, Jr., G. O. Onyi, V. De Rosas, and R. J. Wallace III. 1992. Activities of four macrolides, including clarithromycin, against Mycobacterium fortuitum, Mycobacterium chelonae, and M. chelonae-like organisms. Antimicrob. Agents Chemother. 36:180-184.

8. Chaisson, R. C., C. A. Benson, M. P. Dube, L. B. Heifets, J. A. Korvick, S. Elkin, T. Smith, C. Craft, F. R. Sattler, and the AIDS Clinical Trials Group Protocol 157 Study Team. 1994. Clarithromycin therapy for bacteremic $M y$ cobacterium avium complex disease. Ann. Intern. Med. 121:905-911.

9. Chu, S.-Y., L. T. Sennello, and R. C. Sonders. 1991. Simultaneous determination of clarithromycin and 14®-hydroxyclarithromycin in plasma and urine using high-performance liquid chromatography with electrochemical detection. J. Chromatogr. 571:199-208.

10. Clancey, J. K., O. G. Dodge, H. F. Lunn, and M. L. Oduozi. 1961. Mycobacterial skin ulcers in Uganda. Lancet ii:951-954.

11. Dautzenberg, B., C. Truffot, S. Legris, M.-C. Meyohas, H. C. Berlie, A. Mercat, S. Chevret, and J. Grosset. 1991. Activity of clarithromycin against Mycobacterium avium infection in patients with the acquired immune deficiency syndrome. Am. Rev. Respir. Dis. 144:564-569.

12. Fernandes, P. B., D. J. Hardy, D. McDaniel, C. W. Hanson, and R. N. Swanson. 1989. In vitro and in vivo activities of clarithromycin against $M y$ cobacterium avium. Antimicrob. Agents Chemother. 33:1531-1534.

13. Flood, P., A. Street, P. O'Brien, and J. Hayman. 1994. Mycobacterium ulcerans infection on Phillip Island, Victoria. Med. J. Aust. 160:160.

14. Franzblau, S. G., and R. C. Hastings. 1988. In vitro and in vivo activities of macrolides against Mycobacterium leprae. Antimicrob. Agents Chemother. 32:1758-1762.

15. Gevaudan, M. J., C. Bollet, M. N. Mallet, and P. de Micco. 1991. Mesure de l'activité intramacrophagique d'associations d'antibiotiques vis-à-vis de $M y$ cobacterium marinum. Pathol. Biol. 39:436-441.

16. Gevaudan, M. J., C. Bollet, M. N. Mallet, and P. de Micco. 1993. In-vitro evaluation of clarithromycin, temafloxacin, and ethambutol in combination against Mycobacterium avium complex. J. Antimicrob. Chemother. 31:725730 .

17. Hafner, R., J. Bethel, M. Power, B. Landry, M. Banach, L. Mole, H. C. Standiford, S. Follansbee, P. Kumar, R. Raasch, D. Cohn, D. Mushatt, and G. Drusano. 1998. Tolerance and pharmacokinetic interactions of rifabutin and clarithromycin in human immunodeficiency virus-infected volunteers. Antimicrob. Agents Chemother. 42:631-639.

18. Havel, A., and S. R. Pattyn. 1975. Activity of rifampicin on Mycobacterium ulcerans. Ann. Soc. Belge Med. Trop. 55:105-108.

19. Heifets, L. 1988. Qualitative and quantitative drug-susceptibility tests in mycobacteriology. Am. Rev. Respir. Dis. 137:1217-1222.

20. Heifets, L. B., P. J. Lindholm-Levy, and R. D. Comstock. 1992. Clarithromycin minimal inhibitory and bactericidal concentrations against Mycobacterium avium. Am. Rev. Respir. Dis. 145:856-858.

21. Josse, R., A. Guédénon, H. Darie, S. Anagonou, F. Portaels, and W. M. Meyers. 1995. Les infections cutanées à Mycobacterium ulcerans: ulcères de Buruli. Med. Trop. 55:363-373.

22. Kiehn, T. E., and M. White. 1994. Mycobacterium haemophilum: an emerging pathogen. Eur. J. Clin. Microbiol. Infect. Dis. 13:925-931.

23. Lavalle, P., F. De Ovando, J. Novales, and J. L. Ayala. 1981. Micobacteriosis cutanea ulcerosa dermatologia. Dermatol. Rev. Mex. 25:325-347.

24. Marston, B. J., M. O. Diallo, C. R. Horsburgh, I. Diomande, M. Z. Saki, J. M. Kanga, G. Patrice, H. B. Lipman, S. M. Ostroff, and R. Good. 1995. Emergence of Buruli ulcer disease in the Daloa region of Côte d'Ivoire. Am. J. Trop. Med. Hyg. 52:219-224.

25. Maxson, S., G. E. Schutze, and R. F. Jacobs. 1994. Mycobacterium abscessus osteomyelitis: treatment with clarithromycin. Infect. Dis. Clin. Prac. 3:203205.

26. Meyers, W. M., W. M. Shelly, and D. H. Connor. 1974. Heat treatment of Mycobacterium ulcerans infections without surgical excision. Am. J. Trop. Med. Hyg. 23:924-929.

27. Mor, N., and L. Heifets. 1993. MICs and MBCs of clarithromycin against Mycobacterium avium within human macrophages. Antimicrob. Agents Chemother. 37:111-114.

28. Mushatt, D. M., and R. S. Witzig. 1995. Successful treatment of Mycobacterium abscessus infections with multidrug regimens containing clarithromycin. Clin. Infect. Dis. 20:1441-1442.

29. Pattyn, S. R., and J. Royackers. 1965. Traitement de l'infection expérimentale de la souris par Mycobacterium ulcerans et Mycobacterium balnei. Ann. Soc. Belge Med. Trop. 45:31-38.

30. Periyakoil, V., and C. Krasner. 1996. Mycobacterium abscessus osteomyelitis following a plantar puncture wound. Clin. Infect. Dis. 23:651-653.

31. Portaels, F., P. A. Fonteyne, H. De Beenhouwer, P. de Rijk, A. Guédénon, J. 
Hayman, and W. M. Meyers. 1996. Variability in the 3' end of the 16S rRNA sequence of the species Mycobacterium ulcerans is related to geographic origins of isolates. J. Clin. Microbiol. 34:962-965.

32. Rastogi, N., and K. S. Goh. 1992. Effect of $\mathrm{pH}$ on radiometric MICs of clarithromycin against 18 species of mycobacteria. Antimicrob. Agents Chemother. 36:2841-2842.

33. Rastogi, N., K. S. Goh, and V. Labrousse. 1992. Activity of clarithromycin compared with those of other drugs against Mycobacterium paratuberculosis and further enhancement of its extracellular and intracellular activities by ethambutol. Antimicrob. Agents Chemother. 36:2843-2846.

34. Stanford, J. L., and I. Phillips. 1972. Rifampicin in experimental Mycobacterium ulcerans infection. J. Med. Microbiol. 5:39-45.

35. Stauffer, F., O. Dörtbudak, and E. Lahonik. 1991. In vitro testing of clarithromycin in combination with ethambutol and rifampicin against Mycobacterium avium complex. Infection 19:343-344.
36. Tessier, M.-H., J.-C. Amoric, F. Méchinaud, D. Dubesset, P. Litoux, and J.-F. Stalder. 1994. Clarithromycin for atypical mycobacterial lymphadenitis in non-immunocompromised children. Lancet 344:1778.

37. Wallace, R. J., Jr., B. A. Brown, and G. O. Onyi. 1992. Skin, soft tissue, and bone infections due to Mycobacterium chelonae: importance of prior corticosteroid therapy, frequency of disseminated infections, and resistance to oral antimicrobials other than clarithromycin. J. Infect. Dis. 166:405-412.

38. Wallace, R. J., Jr., D. Tanner, P. J. Brennan, and B. A. Brown. 1993. Clinical trial of clarithromycin for cutaneous (disseminated) infection due to $\mathrm{Myco}$ bacterium chelonae. Ann. Intern. Med. 119:482-486.

39. Yajko, D. M., J. Kirihara, C. Sanders, P. Nassos, and W. K. Hadley. 1988. Antimicrobial synergism against Mycobacterium avium complex strains isolated from patients with acquired immune deficiency syndrome. Antimicrob. Agents Chemother. 32:1392-1395. 